\title{
Near-Field Angular Distributions of High Velocity Ions for Low-Power Hall Thrusters
}

\author{
Regina M. Sullivan \\ California Institute of Technology \\ 1200 E. California Blvd., MC 205-45 \\ Pasadena, CA 91106 \\ 818-354-6128 \\ rsulli@caltech.edu
}

\author{
Allison Yost \\ University of New Hampshire \\ Durham, NH 03824 \\ alo29@unh.edu
}

\author{
Lee K. Johnson \\ Jet Propulsion Laboratory \\ 4800 Oak Grove Drive, MS 125-109 \\ Pasadena, CA 91109 \\ 818-354-9878 \\ Lee.K.Johnson@jpl.nasa.gov
}

\begin{abstract}
Experimental angular distributions of highenergy primary ions in the near-field region of a small Hall thruster between $50-200 \mathrm{~mm}$ downstream of the thruster exit plane at a range of centerline angles have been determined using a highly-collimated, energy-selective diagnostic probe. The measurements reveal a wide angular distribution of ions exiting the thruster channel and the formation of a strong, axially-directed jet of ions along the thruster centerline. Comparisons are made to other experimental determinations as applicable.
\end{abstract}

\section{TABLE OF CONTENTS}

1. INTRODUCTION . .1

2. EXPERIMENTAL APPROACH...............................................2

3. RESULTS AND DISCUSSION ..............................................5

4. Conclusions ......................................................... 7

REFERENCES ....................................................................8

BIOGRAPHY .............................................................8

\section{INTRODUCTION}

Due to their high efficiency and specific impulse, Hall thrusters offer an attractive alternative to traditional chemical propulsion systems. Like other types of electric propulsion devices, these thrusters offer the benefits of low propellant mass and relatively long lifetimes. However, since Hall thrusters produce high-energy ions which can damage surfaces with which they interact, thruster integration is a definite concern. Furthermore, knowledge of ion trajectories is necessary to validate models of thrusters, and also to provide an input condition for plume codes. Therefore, it is important to fully understand the physics governing the production of ions and their subsequent trajectories.

There are two types of Hall thrusters, those with dielectric walls, and those with metallic walls (known as a "thruster with anode layer," or TAL). The type of thruster in this

1. 978-1-4244-2622-5/09/\$25.00 (C2009 IEEE.

2. IEEEAC paper \#1474, Version 4, Updated Jan 19, 2009.

study is the dielectric type. In a Hall thruster, thrust is generated by ionizing and accelerating a propellant, typically a noble gas such as xenon, using perpendicular electric and magnetic fields. As illustrated in Figure 1, a typical Hall thruster with dielectric walls consists of an insulated cylindrical channel across which there is applied a region of radial magnetic field, as well as an internal anode surface and an external electron-emitting cathode.

During operation, electrons from the cathode migrate towards the anode, but in the process encounter the magnetic field. These electrons become caught on radial magnetic field lines and undergo Larmor orbits as well as azimuthal ExB drift. Neutral gas injected from the anode is ionized by the trapped electrons. Because of the presence of the magnetic field and resulting decrease in electron mobility, a primarily axial electric field is set up along the length of the channel. Ions are accelerated by this electric field, to produce an initially annular beam of ions. Electrons from the cathode subsequently neutralize the beam. [1]

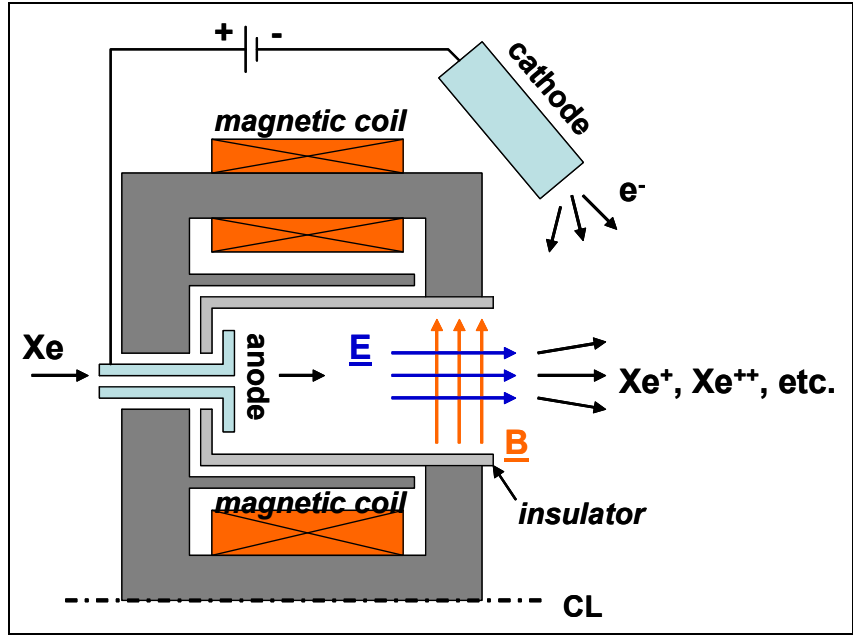

Figure 1 - Cross section of a typical Hall thruster. Rotating the cross section view $360^{\circ}$ about the centerline represents the full thruster with its cylindrical channel. 
As it crosses the exit plane, the beam principally consists of axially directed ions that have been accelerated through nearly the entire potential drop between the cathode and the anode. These ions have the maximum kinetic energy that can be imparted by the device, and are the so-called "high velocity" ions that are the subject of this study. After these ions exit the thruster channel, they interact with the residual magnetic and electric fields in the "near-field" region just outside the exit. Additionally, because the annular ion beam has some divergence, this can cause the beam to interact with itself downstream of the exit plane. This causes a visible "cone" or "jet" to form in the thruster plume, as can be seen in Figure 2.

Previous research has sought to understand the interactions of the ions within the near-field region as well as further downstream in the central jet. For example, several studies using laser-induced fluorescence (LIF) techniques have characterized velocity distributions in the near-field region of 200 and $600 \mathrm{~W}$ Hall thrusters. The thrusters examined in those studies were the commercially available BHT-200 and BHT-HD-600 [2,3,4,5].

The research detailed in this paper seeks to provide experimental data for comparison to existing studies, as well as offering new insights into this area of interest. By creating a detailed map of high velocity ions in the nearfield region of a different type of thruster (an SPT-70), this research will help augment or validate other techniques. Additionally, it may also help to determine whether certain phenomena are unique to specific designs or are typical of Hall thrusters.

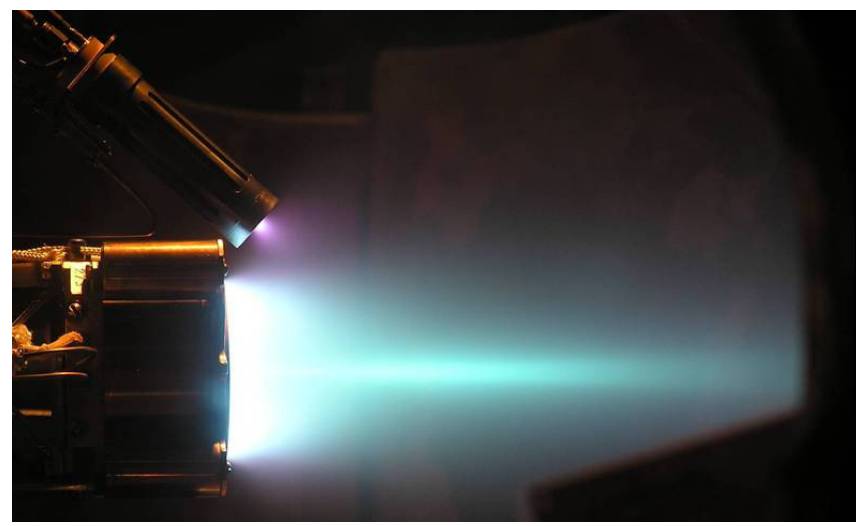

Figure 2 - SPT-70 thruster in operation. Structures in the beam are clearly visible, including the trailing cone/jet.

\section{EXPERIMENTAL APPROACH}

\section{A. Test Facility}

Experiments were carried out in the "Big Green" vacuum facility at the Jet Propulsion Laboratory in Pasadena, CA. Roughly $2 \mathrm{~m}$ in diameter and $3.5 \mathrm{~m}$ in length, this chamber employs two different types of pumps to sustain a range of vacuum pressures. Three diffusion pumps provide a baseline vacuum while additional cryogenic pumps can be turned on to provide additional capability. Typical pressures during thruster operation fall within the $10^{-6}$ torr range.

This facility contains a stationary thruster mount and a twodimensional $(X-Y-\theta)$ translation stage to which diagnostic devices can be attached. The stage can traverse $1.6 \mathrm{~m}$ in the axial ("downstream") direction and $1.0 \mathrm{~m}$ in the transverse direction. An additional stage is mounted on the translation stage, providing 180 degrees of rotation. This allows the researcher to position instruments at a variety of locations within the thruster plume. In this setup, the cathode is located out of the plane of the scans, thus it is expected for the scans to be approximately symmetric about the thruster centerline (relative to Figure 2, the stage travels in a purely horizontal plane passing through the thruster center).

\section{B. SPT-70 Thruster}

The SPT-70 is a Russian-designed thruster that has been in use for several decades [6]. The physics governing its operation are representative of a typical Hall thruster. As described above, and as seen in Figure 3 it consists of an insulated cylindrical channel across which perpendicular and electric and magnetic fields are applied. In the case of the SPT-70, the channel walls consist of an insulator with a nominal outer diameter of $70 \mathrm{~mm}$. Four external magnetic coils provide the necessary radial magnetic field. In this study, a barium oxide hollow cathode was used to provide the electrons for ionization and beam neutralization. Xenon was the gas used to supply both the primary discharge and the cathode.

Under nominal conditions, the SPT-70 operates at approximately $650 \mathrm{~W}$, with a discharge voltage of $300 \mathrm{~V}$ and a discharge current of $2.17 \mathrm{~A}$. However, the thruster can be run successfully at substantially lower power levels. In this study the SPT-70 was run at two operating points, $200 \mathrm{~W}$ and $650 \mathrm{~W}$. The lower power level $(200 \mathrm{~W}$, with a $250 \mathrm{~V}$ and $0.8 \mathrm{~A}$ discharge) was chosen to correspond with the nominal operating point of a BHT-200 Hall thruster, for comparison with existing data. 


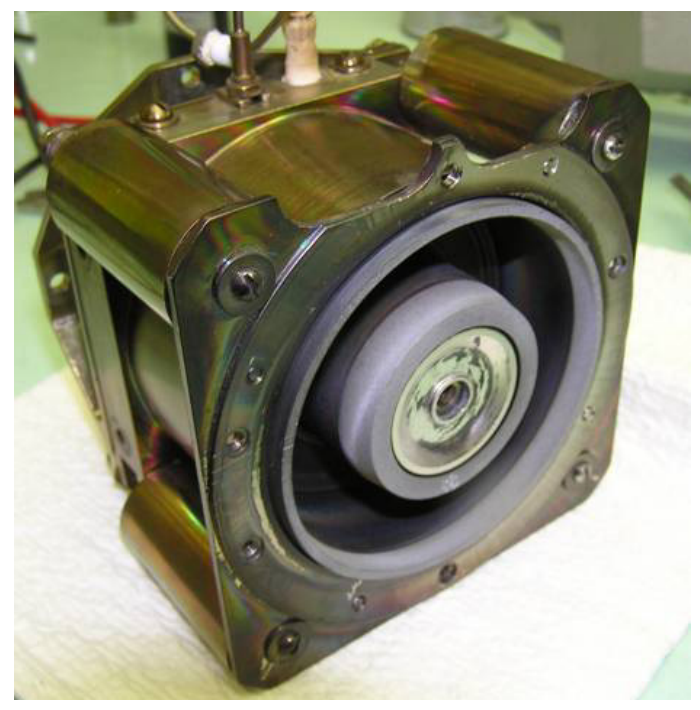

Figure 3 - Close up of the SPT-70.

\section{Collimated ExB Velocity Filter}

A collimated ExB velocity filter was used to determine the flux of ions with a given velocity at a given location in the thruster plume. As shown in Figure 4, in an ExB filter a set of perpendicular electric and magnetic fields are used to filter out undesired velocities. According to the Lorentz equation:

$$
\underline{F}=q_{i}\left(\underline{E}+\underline{v}_{i} x \underline{B}\right)
$$

Where $\underline{F}$ is the force on the ion, $q_{i}$ is its charge, $\underline{v}_{i}$ is its velocity, $\underline{E}$ is the applied electric field and $\underline{B}$ is the applied magnetic field. So if the force on the ion is set to zero, and given that the electric and magnetic field are perpendicular to each other and to the incident velocity, this equation reduces to:

$$
v_{i}=\frac{E}{B}
$$

Therefore, ions with a velocity equal to $\mathrm{E} / \mathrm{B}$ pass through the filter without being deflected. By scanning over a range of $\mathrm{E} / \mathrm{B}$ values, one can thus build up a velocity distribution for the ions. Additionally, one can set the $\mathrm{E} / \mathrm{B}$ value to look at ions with a specific velocity. In this study, the $\mathrm{E} / \mathrm{B}$ value has been set at a value corresponding to the high velocity $\mathrm{Xe}^{+}$ions (i.e. $\mathrm{Xe}^{+}$ions that have been accelerated through the full potential drop within the thruster).

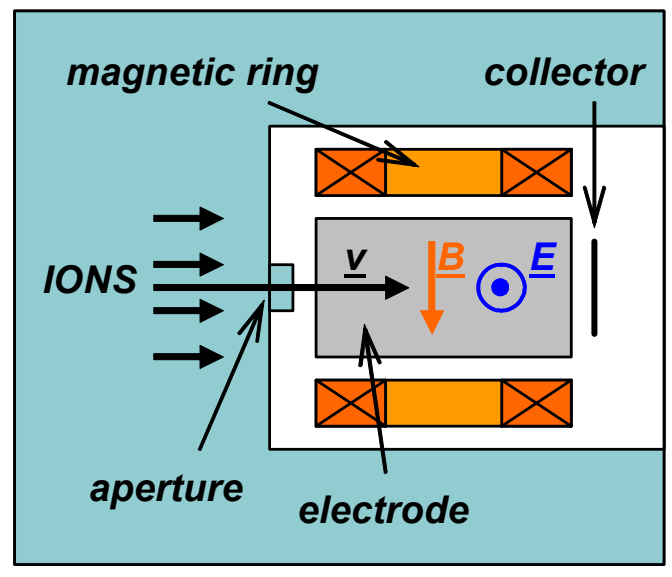

Figure 4 - ExB filter schematic. For a particle to pass through undeflected, $\underline{\mathrm{v}} \times \underline{\mathrm{B}}$ and E must balance.

The velocity filter used in this case was a Colutron 300, which uses an electromagnet to provide a magnetic field ranging from 0 to $0.11 \mathrm{~T}$. Two perpendicular plates generate the electric field, and a series of metal shims is used to shape the electric field between the plates. In the case of the instrument used in this study, two apertures were mounted in front of the filter, resulting in an angle of acceptance of $0.8 \mathrm{deg}$ (full angle, the apertures both have a diameter of $1 \mathrm{~mm}$ and are separated by a distance of 145 $\mathrm{mm}$ ). A simple carbon collector, on which the nondeflected ion current was measured, was mounted behind the filter. A photograph of this particular probe can be seen in Figure 5.

It is important to note that current measured by this probe is the current into $0.8 \mathrm{deg}$, due to the collimation provided by the apertures. In this paper, the ExB filter current density values are given in $\mathrm{A} / \mathrm{m}^{2}$, and simply represent the current into $0.8 \mathrm{deg}$, divided by aperture area (i.e. the collimated, rather than the total, non-collimated current density).

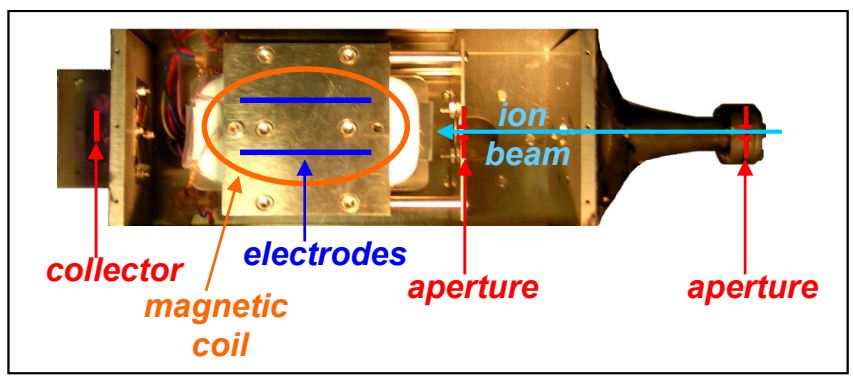

Figure 5 - ExB filter used in the study. Note that the aperture separation is $145 \mathrm{~mm}$. 


\section{Faraday Probe}

A miniature faraday probe was used to measure ion current density in the thruster plume. As shown in Figure 6, this type of device consists of an internal collector and an outer guard ring. Both are made of a conducting material, and are electrically isolated from one another. During operation, both are biased at a low negative voltage $(-20 \mathrm{~V})$ to reject plasma. The purpose of the guard ring is to avoid a curved plasma sheath at the probe edges. In this study, a faraday probe with a diameter of $1.6 \mathrm{~mm}$ was used. Its angle of acceptance is much larger than the ExB filter as it approximately follows a projected area cosine law (i.e. unlike the ExB prob, it is not collimated).

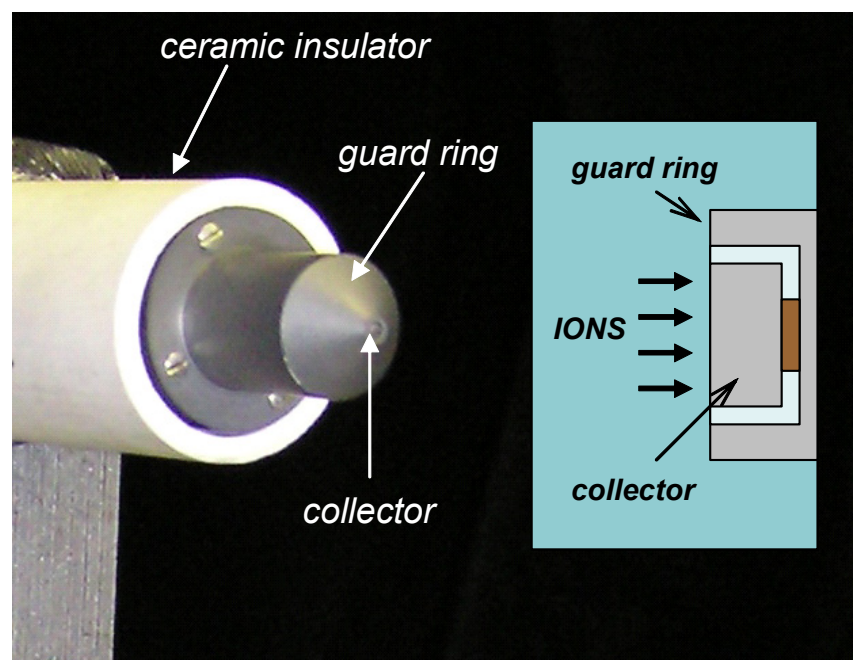

Figure 6 - Faraday probe schematic and photograph of device used in the study. This particular design employs a conical guard ring. Note that unlike the ExB filter, all forward velocities are accepted by the faraday probe.

\section{E. Test Conditions}

Experimental tests were conducted at two different power levels: $200 \mathrm{~W}$ and $650 \mathrm{~W}$. At each of these operating points, scans of the thruster plume were taken in both the axial and transverse directions. For all the scans, the ExB probe was set such that the accepted velocity $\left(v_{i}=E / B\right)$ corresponded to the experimentally determined peak of the high velocity $\mathrm{Xe}^{+}$ions. Table 1 is a matrix of the test conditions examined using the ExB probe in the study. Figure 7 provides an illustration of the scans catalogued in Table 1. Transverse faraday probe scans were also taken at different axial locations, but only at 0 deg relative to the thruster centerline.
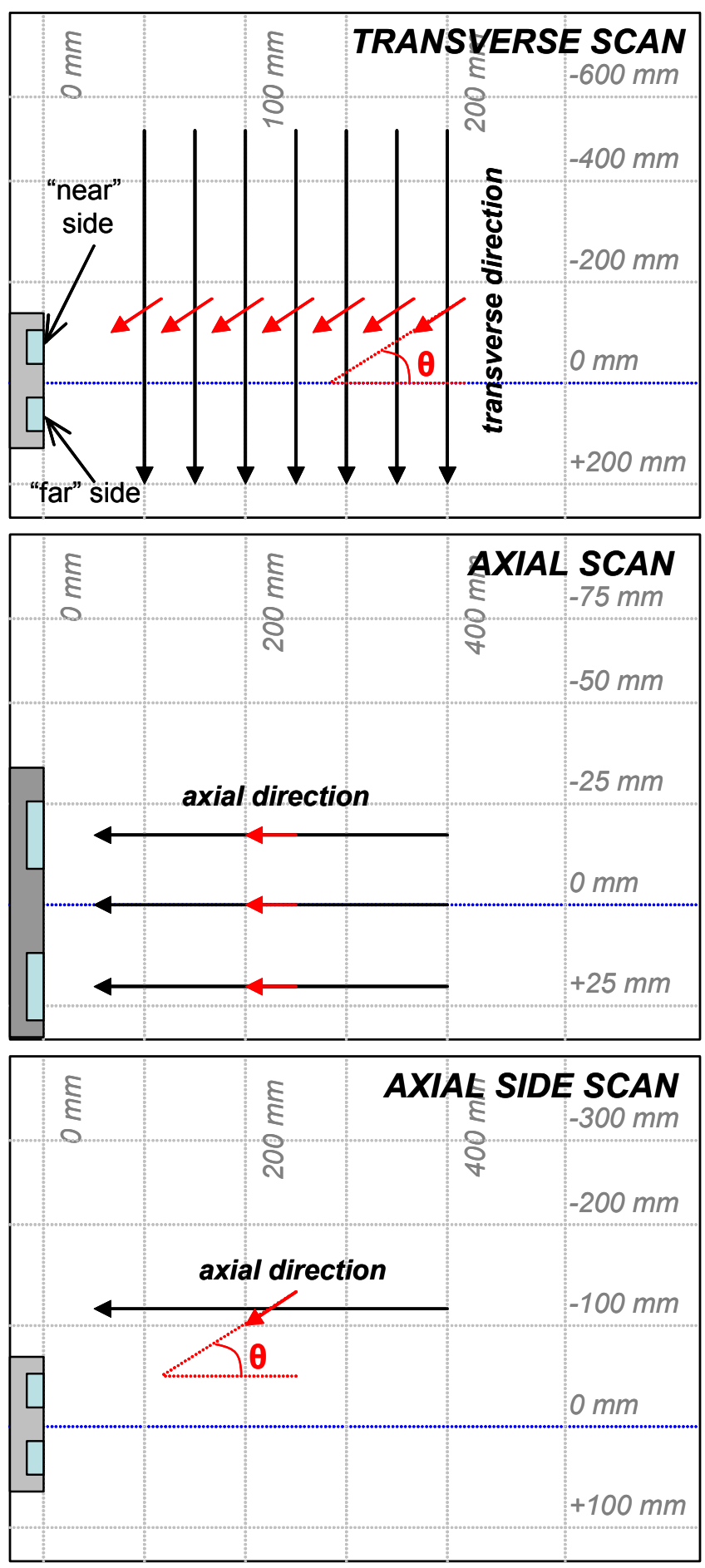

Figure 7 - Scans as catalogued in Table 1. Not to scale; thruster is shown in light blue. For the transverse scans, the axial location and the angle $(\theta)$ are fixed while the probe is moved perpendicular to the thruster center line. For the axial scans, the transverse location is fixed and the angle is set to $0^{\circ}$ while the probe is moved toward the thruster exit plane. For the axial side scans, the transverse location is fixed at $-127 \mathrm{~mm}$ and the angle is fixed while the probe is moved parallel to the thruster center line. Note that the cathode plane is orthogonal to the plane of the scans. 


\section{RESULTS AND DISCUSSION}

\section{A. Transverse Scans}

\section{(1) $200 \mathrm{~W}$ condition}

(a) ExB on vs. off

Scans were taken with the ExB probe on and off to determine what proportion of the distribution represents high velocity $\mathrm{Xe}^{+}$ions (single ions accelerated through the full potential of the thruster) and what proportion represents lower velocity ions (ions accelerated through only part of the potential, or slowed by various processes) or ions of higher charge $\left(\mathrm{Xe}^{2+}, \mathrm{Xe}^{3+}\right.$, etc.). When "on", the ExB filter measures only the high velocity $\mathrm{Xe}^{+}$ions (the $\mathrm{Xe}^{+}$ion peak was determined experimentally), and when "off" it measures all ions (subject to the acceptance angle of the device), regardless of velocity.

As can be seen in Figure 8, although the current densities are lower when the ExB filter is on, the data follow the same trends as when the ExB filter is off. Figure 8 also shows that the high-velocity ion current density is over $50 \%$ of the total ion current density, suggesting that the axially directed portion of the beam consists primarily of high velocity ions.

\section{(b) $50 \mathrm{~mm}$ axial distance}

Figure 9 shows the results of transverse scans for the $200 \mathrm{~W}$ condition, at different angles relative to the centerline, for the $50 \mathrm{~mm}$ case (and with the ExB filter on). The projected channel locations are also shown, since for a transverse scan at an angle, ions originating from the channel will not show up between -35 and $+35 \mathrm{~mm}$. (This occurs because of the geometry of the trajectories; an ion exiting at a certain angle and traveling a certain axial distance will move in the transverse direction.) By plotting the projection, one can see from what part of the thruster the ions originated, assuming that the ions follow field-free trajectories outside the thruster.

Additionally, it is important to note that because of the direction in which the transverse scans are performed (see Figure 7), the probe is always going to pass by one side of the channel first. We will call the side it passes by first the "near" side, and the other channel the "far" side. Due to the geometry of the scan, ions that originate from the near side and enter the angled ExB probe must be have an outward radial velocity component, and ions that originate from the far side must inward radial component. In the plots in Figure 9 the near side is plotted on the left, and the far side is on the right. From this point on we will refer to the near side ions as "outward-radial" ions and the far side ions as "inward-radial" ions.

At 0 deg, there are two roughly symmetric peaks that line up with the centers of the channel. This suggests that at 50 $\mathrm{mm}$, most of the axially-directed, high velocity ion current density originates within the channel, and that both sides of the channel contribute equally. At $10 \mathrm{deg}$, in contrast, the far side of the channel produces more ion current density, as shown by the larger area under the right peak. Also, the data show that not all inward-radial ions have taken direct paths from the channel to the probe; rather their trajectories have been bent (this is seen by the ion current density that appears interior to the projected channel location). The same phenomenon is present at 20 and $30 \mathrm{deg}$. At $40 \mathrm{deg}$, the overall high velocity current density starts to decrease, and drops off considerably at $50 \mathrm{deg}$, although there are still high velocity ions present at $60 \mathrm{deg}$.

These results indicate for the collimated ExB probe at 50 $\mathrm{mm}$, most of the angle-resolved high velocity ion current density falls between angles of 0 and $50 \mathrm{deg}$, and that the majority of current density at angles of 10 to $40 \mathrm{deg}$ is directed inward, rather than outward. Also, at these angles there is a substantial proportion of current density that has not traveled directly from the channel. This suggests that there is a mechanism outside the exit plane which is pushing the ions inward. The data provided here thus offer clues as to the size and direction of an external electric field. Possible explanations include the residual electric field that exists outside the channel, as well as a disparity that exists in ion density outside the channel (since no ions are produced at the center of the thruster exit plane). A residual or induced magnetic field is not sufficient to explain these results.

Figure 10 shows the corresponding faraday trace at $50 \mathrm{~mm}$ and with zero angle relative to the centerline. In this trace, there is a single sharp spike at the center, and the individual channel peaks are not discernable. This suggests that at 50 $\mathrm{mm}$, most of the total ion current density is due to a central jet of ions rather than an annular ring, meaning at this distance the transition from one to another has already occurred. Comparing this to the ExB data suggests that although there is still a ring of axially directed ions, the nonaxial contributions that make up the jet are significantly larger.

\section{(c) $100 \mathrm{~mm}$ axial distance}

Figure 11 shows the results of transverse scans for the 200 $\mathrm{W}$ condition, at different angles relative to the centerline, for the $100 \mathrm{~mm}$ case (and with the ExB filter on). At 0 deg, rather than two distinct peaks, there is a central peak with "shoulders" that correspond to the two sides of the channel. At $10 \mathrm{deg}$, one sees the same phenomena that were present at $50 \mathrm{~mm}$, i.e. a larger contribution to the high velocity ion current density by the inward-radial ions, and ions not following straight-line paths. At 20 and $30 \mathrm{deg}$, the inwardradial current density is larger than the outward-radial current density.

Comparing this data to the $50 \mathrm{~mm}$ case suggests that the angle-resolved high velocity ion current density falls off 
more rapidly as the angle increases. The majority of ion current leaves the thruster at angles less than $30 \mathrm{deg}$, whereas at $50 \mathrm{~mm}$, a significant proportion of ion current density is seen at $40 \mathrm{deg}$. Thus, the high velocity ion beam appears to be more convergent at $100 \mathrm{~mm}$.

Figure 12 shows the corresponding faraday probe trace at $100 \mathrm{~mm}$ and with zero angle relative to the centerline. The overall density is smaller than at $50 \mathrm{~mm}$, which is to be expected, and the peak is less sharp. This suggests that the beam is less convergent at $100 \mathrm{~mm}$, which is at odds with the conclusion reached from the ExB data. However it is important to note that the faraday probe accepts all forward velocities, so the peak may appear wider due to contributions from lower velocity ions.

\section{(2) $650 \mathrm{~W}$ condition}

\section{(a) $50 \mathrm{~mm}$ axial distance}

Figure 13 shows the results of transverse scans at $650 \mathrm{~W}$ at different angles relative to the centerline, for the $50 \mathrm{~mm}$ case (and with the ExB filter on). This shows roughly the same trends as the $200 \mathrm{~W}$ case: larger inward-radial current density, substantial deviation from straight line trajectories as the angle increases.

Figure 14 shows the corresponding faraday probe trace at $50 \mathrm{~mm}$ and with zero angle relative to the centerline. In this trace, there is a large peak at the center, with "shoulders" on the distribution that appear to correspond to the channel, and which are not present in the $200 \mathrm{~W}$ case. This suggests that at $650 \mathrm{~W}$, at $50 \mathrm{~mm}$ the annular ring makes a proportionally greater contribution to the total ion current density than it does in the $200 \mathrm{~W}$ case. Thus, it appears that the beam takes a longer distance to transition from ring to jet as the power is increased.

\section{(b) $100 \mathrm{~mm}$ axial distance}

Figure 15 shows the results of transverse scans for the 650 $\mathrm{W}$ condition, at different angles relative to the centerline, for the $100 \mathrm{~mm}$ case (and with the ExB filter on). Again, this shows roughly the same trends as were seen at the 200 $\mathrm{W}$ condition.

Figure 16 shows the shows the corresponding faraday probe trace at $100 \mathrm{~mm}$ and with zero angle relative to the centerline. Unlike the $50 \mathrm{~mm}$ case, there are no shoulders in the trace; rather there is a single peak at the center of the distribution. This peak is higher in magnitude than the central peak in the $50 \mathrm{~mm}$ case, so the central jet has a greater total current density at $100 \mathrm{~mm}$ than at $50 \mathrm{~mm}$.

\section{B. Axial Scans}

\section{(1) ExB filter parallel to thruster centerline}

Figure 17 shows the results of the axial scans for the $200 \mathrm{~W}$ and $650 \mathrm{~W}$ cases, with the ExB filter on. Along the channel center the $\mathrm{Xe}^{+}$angle-resolved high velocity ion current density drops off monotonically. However, along the thruster center, the current density peaks at roughly $125 \mathrm{~mm}$ downstream of the exit plane, and has a precipitous drop at roughly $330 \mathrm{~mm}$. This is strong evidence for an axially directed central jet that is made up of high-velocity $\mathrm{Xe}^{+}$ ions, as discussed previously.

It is also worth noting that along the channel centerline, the $650 \mathrm{~W}$ case behaves quite differently than the $200 \mathrm{~W}$ case. This can be seen by comparing Figure 13 to Figure 17. In Figure 13, along the channel center there is an current density of about $500 \mathrm{~A} / \mathrm{m}^{2}$ at $0 \mathrm{deg}$, but in Figure 17 at 50 $\mathrm{mm}$ the current density is $50 \mathrm{~A} / \mathrm{m}^{2}$. One likely cause of this anomaly is that during an axial scan, the probe spends the duration of the scan directly in front of the thruster channel. This could lead to neutrals building up in front of the device, blocking a portion of the ion current. (In contrast, during a transverse scan the probe only spends a small fraction of the scan directly in front of the thruster channel). In the $200 \mathrm{~W}$ case, this discrepancy was not seen, most likely due to the lower ion and neutral densities.

Along the thruster centerline, the results at $650 \mathrm{~W}$ are similar to those at $250 \mathrm{~W}$. Although the shape of the distribution is different, it still peaks at about $125 \mathrm{~mm}$ downstream, then decreases as axial position increases. Again, this indicates the presence of an axially directed jet. It is important to note that in both the 200 and $650 \mathrm{~W}$ cases, the largest high velocity ion current density that is axially directed is in a location that cannot have come directly from the channel. Therefore, there must be a mechanism within the near field that is changing ion trajectories as they leave the channel. As mentioned in the analysis of the transverse data, potential gradients caused by the residual electric field or non-uniform plasma density might influence ion motion in the near field.

\section{(2) ExB filter at an angle}

Figure 18 shows the results of the axial side scans for the $200 \mathrm{~W}$ case, with the ExB filter on. As in the case of the transverse scans at an angle, it is important to note where ions generated within the thruster channel are expected to end up on the scan. In these plots the near channel is on the left and the far channel is on the right.

At angles from 30 to $60 \mathrm{deg}$, there are two clear peaks in the data. It should be noted that at $30 \mathrm{deg}$, there is a substantial ion current density caused by ions that have not followed a straight line path from the far channel to the probe. The magnitude of these peaks decreases as the angle increases.

The axial side scans are illuminating for several reasons. Figure 18 shows that at $30 \mathrm{deg}$, the magnitude of the two peaks is not uniform, suggesting, as mentioned before, that more ions may be moving with an inwardly radial component. Figure 18 also indicates that even at high 
angles off of the thruster centerline (60 deg), there is still a significant population of fast moving $\mathrm{Xe}^{+}$ions. A similar result was seen in previous studies of the BHT-200 Hall thruster plume [8].

\section{Additional Faraday probe data}

Figure 19 shows the results of several transverse Faraday probe scans, taken at 15,50 , and $200 \mathrm{~mm}$ away from the thruster, for both the 200 and $650 \mathrm{~W}$ conditions. These scans clearly reveal the transition between the annular beam and the central jet. In the $200 \mathrm{~W}$ case, the distribution transitions from two broad peaks with a small central peak at $15 \mathrm{~mm}$, to a sharp central peak at $50 \mathrm{~mm}$. As distance is increased further, the flux decreases and the central peak becomes more broad. In the $650 \mathrm{~W}$ case, the peaks at 15 $\mathrm{mm}$ are narrow, and at $50 \mathrm{~mm}$ the beam has not quite fully transitioned to the central jet. At $200 \mathrm{~mm}$ the central peak is much smaller and broader. As suggested by the ExB data, the faraday probe results also suggest that the transition between ring and jet occurs over a longer distance for the $650 \mathrm{~W}$ case.

\section{Comparison to previous studies}

As mentioned in the introduction, several studies have been conducted with the goal of measuring ion velocity distributions in the near-field of a Hall thruster. The thrusters examined in those efforts were the BHT-200 [2,3] and the BHT-HD-600 [4,5]. Both of those thrusters are manufactured by the Busek Co., Inc.. The underlying physics of those thrusters should be similar to that of the SPT-70, although there are differences in geometry and operating parameters. The BHT-200 is designed to operate nominally at $200 \mathrm{~W}$, while the SPT-70 operates ideally at $650 \mathrm{~W}$.

Despite these differences, it is expected that all of these thrusters should share some of the same fundamental physics. In the previous studies, most of the measurements were taken very close to the thruster exit plane (less than 20 $\mathrm{mm}$ from the exit plane). Nonetheless, some of the data were taken at $60 \mathrm{~mm}$ and $100 \mathrm{~mm}$, which offer points of comparison for this study.

For the BHT-200, at a distance of $100 \mathrm{~mm}$ it was seen that ions travel outward from the outer edge of the channel, at an angle of about $12 \mathrm{deg}$. Ions originating from the inner edge of the channel, in contrast, move outward at an angle of 6 deg [3]. This suggests that at $100 \mathrm{~mm}$ the largest ion current density would be seen at an angle between 6 and 12 deg. For the SPT-70 operating at $200 \mathrm{~W}$, most of the current density is seen between 0 and $20 \mathrm{deg}$, dropping off substantially as the angle is increases above $20 \mathrm{deg}$. This is consistent with the results from the BHT-200 study.

Overall, the BHT-200 data seems to complement the SPT70 data at $200 \mathrm{~W}$. This is somewhat surprising because the SPT-70 is not designed to operate at this power level, while the BHT-200 is optimized for this condition. As a result, one might expect that the SPT-70 beam to be less convergent; however, the data do not support this assertion.

In the case of the BHT-600, at a distance of $60 \mathrm{~mm}$ it was seen that ions travel outward from the outer edge of the channel, at an angle of about $10 \mathrm{deg}$. Ions from the inner channel travel inward from the outer edge of the channel at an angle of about $10 \mathrm{deg}$. This suggests that the maximum ion current would be seen at about $10 \mathrm{deg}$. Additionally, at $60 \mathrm{~mm}$, the ring has not yet converged on itself to form the central jet [5]. For the SPT-70 operating at $650 \mathrm{~W}$, most of the ion current is produced at angles between 0 and $20 \mathrm{deg}$, which is consistent with the BHT-600 results. However, the data in Figure 14 shows the presence of the central jet, suggesting that the transition may occur over a shorter distance in the SPT-70.

At a distance of $100 \mathrm{~mm}$, the previous data suggest that the average angle of ion trajectories for the BHT-600 is smaller, roughly $5 \mathrm{deg}$. This is somewhat consistent with the SPT70 data, as the beam is more convergent at $100 \mathrm{~mm}$ then at $50 \mathrm{~mm}$ (most of the ion current is produced at 0 to $10 \mathrm{deg}$ at $100 \mathrm{~mm}$, compared to 0 to $20 \mathrm{deg}$ at $50 \mathrm{~mm}$ ).

\section{Conclusions}

The results presented here suggest the presence of several phenomena within the near-field and plume regions of the SPT-70 Hall thruster. In particular, there is evidence for a wide angular distribution of high velocity ion trajectories as well as the existence of an axially-directed jet of ions along the thruster centerline. The evolution between the annular beam and the central jet is clearly seen as one increases axial distance, and there is evidence that this transition occurs over a longer distance at higher power. Additionally, the experiment revealed the rather unexpected result that the inwardly directed ion current density is larger than the outwardly directed ion current density. Furthermore, the results show that there is a substantial current density due to ions that have not traveled in straightline paths, indicating that there is a mechanism outside the exit plane that is influencing ion trajectories. Finally, although the overlap between existing LIF data and this data is limited, a comparison of the two sets suggests that similar observations have been seen in both.

Future work should strive to determine causes of ion trajectories in the near field. This goal could be accomplished by first comparing these results to data from Hall thruster simulations, and then testing possible hypotheses by adding additional physics to the simulation. HPHall, a well-researched Hall thruster code, is a logical place to start, but new code may have to be developed. Eventually, it is hoped that the data provided by this study 
will help to refine Hall thruster models, with the objective of reproducing structures seen in the experimental data.

\section{REFERENCES}

[1] D.M. Goebel and I. Katz, Fundamentals of Electric Propulsion: Ion and Hall Thrusters, Hoboken: John Wiley \& Sons, Inc., 2008.

[2] W. Hargus and M. Nakles, "Evolution of the Ion Velocity Distribution in the Near Field of the BHT-200-X3 Hall Thruster," AIAA/ASME/SAE/ASEE Joint Propulsion Conference Proceedings, July 9-12, 2006.

[3] W. Hargus and C. Charles, "Near Exit Plane Velocity Field of a 200-Watt Hall Thruster," Journal of Propulsion and Power, Vol. 24, No. 1, Jan./Feb. 2008.

[4] M. Nakles and W. Hargus, "Background Pressure Effects on Internal and Near-field Ion Velocity Distribution of the BHT-600 Hall Thruster," AIAA/ASME/SAE/ASEE Joint Propulsion Conference Proceedings, July 21-23, 2008.

[5] W. Hargus and C. Charles, "Near Plume Laser Induced Fluorescence Velocity Measurements of a $600 \mathrm{~W}$ Hall Thruster," AIAA/ASME/SAE/ASEE Joint Propulsion Conference Proceedings, July 21-23, 2008.

[6] O. A. Gorshkov, et. al, "Activity of Russian Space Agency in the Field of Electric Propulsion," AIAA/ASME/ SAE/ASEE Joint Propulsion Conference Proceedings, July 13-15, 1998.

[7] R. R. Hofer, J. M.Haas, J.M., and A. D. Gallimore, "Ion Voltage Diagnostics in the Far-Field Plume of a HighSpecific Impulse Hall Thruster," AIAA/ASME/ SAE/ASEE Joint Propulsion Conference Proceedings, July 20-23, 2003.

[8] R. M. Sullivan and L. K. Johnson, "Investigation of High-Energy Ions with High-Angle Trajectories in Hall Thruster Plumes," International Electric Propulsion Conference Proceedings, Sept. 17-20. 2007.

\section{BIOGRAPHY}

Regina Sullivan is a PhD candidate at Caltech who primarily conducts her research at JPL. Her current research interests include Hall thruster channel, near-field, and plume physics. She received a S.B from MIT in Aerospace Engineering in 2005, and a M.S. from Caltech in Aeronautics in 2006.

Allison Yost is an undergraduate student in Mechanical Engineering at the University of New Hampshire. She spent the summer of 2008 working on Hall thruster plume research at JPL.

Lee Johnson is senior researcher at JPL. His current research interests include Hall thruster plume dynamics and environmental interactions. He has overseen research on several flight projects involving electric propulsion systems. Before coming to JPL, he worked at the Aerospace Corporation. He received his undergraduate degree from Harvey Mudd and his PhD from Rice University.

\section{Acknowledgements}

The authors would like to thank the National Science Foundation Graduate Research Fellowship Program, the Caltech Summer Undergraduate Research Fellowship program, and the Air Force Research Laboratory for their support. 
Table 1 - Summary of scans.

\begin{tabular}{|c|c|c|c|c|c|c|c|}
\hline $\begin{array}{c}\text { Thruster } \\
\text { Operating } \\
\text { Point }\end{array}$ & Type of Scan & $\begin{array}{l}\text { Axial Position } \\
{[\mathrm{mm}]}\end{array}$ & $\begin{array}{c}\text { Transverse Position } \\
{[\mathrm{mm}]}\end{array}$ & $\begin{array}{c}\text { Angle of } \\
\text { ExB Probe } \\
\text { [deg] }\end{array}$ & ExB setting & $\begin{array}{c}\text { Chamber } \\
\text { Pressure } \\
\text { [torr] }\end{array}$ & $\begin{array}{c}\text { Cathode } \\
\text { Float } \\
\text { Voltage [V] }\end{array}$ \\
\hline $\begin{array}{c}200 \mathrm{~W} \\
(250 \mathrm{~V}, 0.8 \\
\mathrm{A}) \\
\end{array}$ & Transverse & $\begin{array}{l}50,75,100 \\
125,150,175, \\
\quad \text { and } 200\end{array}$ & -477 to 223 & $\begin{array}{c}0,10,20,30 \\
40,50,60,70\end{array}$ & $\begin{array}{c}\mathrm{ON} \\
\left(\mathrm{set} \text { at } \mathrm{Xe}^{+}\right. \\
\text {peak location) }\end{array}$ & $2.5 \times 10^{-6}$ & $-15.4 \mathrm{~V}$ \\
\hline $\begin{array}{c}200 \mathrm{~W} \\
(250 \mathrm{~V}, 0.8 \\
\mathrm{A})\end{array}$ & Transverse & $\begin{array}{c}50,75,100 \\
125,150,175 \\
\text { and } 200\end{array}$ & -477 to 223 & $\begin{array}{c}0,10,20,30 \\
40,50,60,70\end{array}$ & $\begin{array}{c}\text { OFF } \\
\text { (no deflection) }\end{array}$ & $2.5 \times 10^{-6}$ & $-15.4 \mathrm{~V}$ \\
\hline $\begin{array}{c}200 \mathrm{~W} \\
(250 \mathrm{~V}, 0.8 \\
\mathrm{A})\end{array}$ & Axial & 400 to 50 & $-27,-4,0$, and +23 & 0 & $\begin{array}{c}\mathrm{ON} \\
\left(\text { set at } \mathrm{Xe}^{+}\right. \\
\text {peak location) }\end{array}$ & $2.5 \times 10^{-6}$ & $-15.4 \mathrm{~V}$ \\
\hline $\begin{array}{c}200 \mathrm{~W} \\
(250 \mathrm{~V}, 0.8 \\
\mathrm{A})\end{array}$ & Axial & 400 to 50 & $-27,-4,0$, and +23 & 0 & $\begin{array}{c}\text { OFF } \\
\text { (no deflection) }\end{array}$ & $2.5 \times 10^{-6}$ & $-15.4 \mathrm{~V}$ \\
\hline $\begin{array}{c}200 \mathrm{~W} \\
(250 \mathrm{~V}, 0.8 \\
\mathrm{A})\end{array}$ & Axial Side & 400 to 50 & -127 & $\begin{array}{c}30,40,50, \\
60,70,80,90\end{array}$ & $\begin{array}{c}\mathrm{ON} \\
\text { (set at } \mathrm{Xe}^{+} \\
\text {peak location) }\end{array}$ & $2.5 \times 10^{-6}$ & $-15.4 \mathrm{~V}$ \\
\hline $\begin{array}{c}200 \mathrm{~W} \\
(250 \mathrm{~V}, 0.8 \\
\mathrm{A})\end{array}$ & Axial Side & 400 to 50 & -127 & $\begin{array}{c}30,40,50, \\
60,70,80,90\end{array}$ & $\begin{array}{c}\text { OFF } \\
\text { (no deflection) }\end{array}$ & $2.5 \times 10^{-6}$ & $-15.4 \mathrm{~V}$ \\
\hline $\begin{array}{c}650 \mathrm{~W} \\
(300 \mathrm{~V}, 2.17 \\
\mathrm{A})\end{array}$ & Transverse & $\begin{array}{c}50,75,100, \\
125, \text { and } 150\end{array}$ & -477 to 223 & $\begin{array}{c}0,10,20,30 \\
40,50,60,70\end{array}$ & $\begin{array}{c}\mathrm{ON} \\
\text { (set at } \mathrm{Xe}^{+} \\
\text {peak location) }\end{array}$ & $6.0 \times 10^{-6}$ & $-35.5 \mathrm{~V}$ \\
\hline $\begin{array}{c}650 \mathrm{~W} \\
(300 \mathrm{~V}, 2.17 \\
\mathrm{A})\end{array}$ & Axial & 400 to 50 & $-27,-4,0$, and +23 & 0 & $\begin{array}{c}\mathrm{ON} \\
\text { (set at } \mathrm{Xe}^{+} \\
\text {peak location) }\end{array}$ & $6.0 \times 10^{-6}$ & $-35.5 \mathrm{~V}$ \\
\hline
\end{tabular}

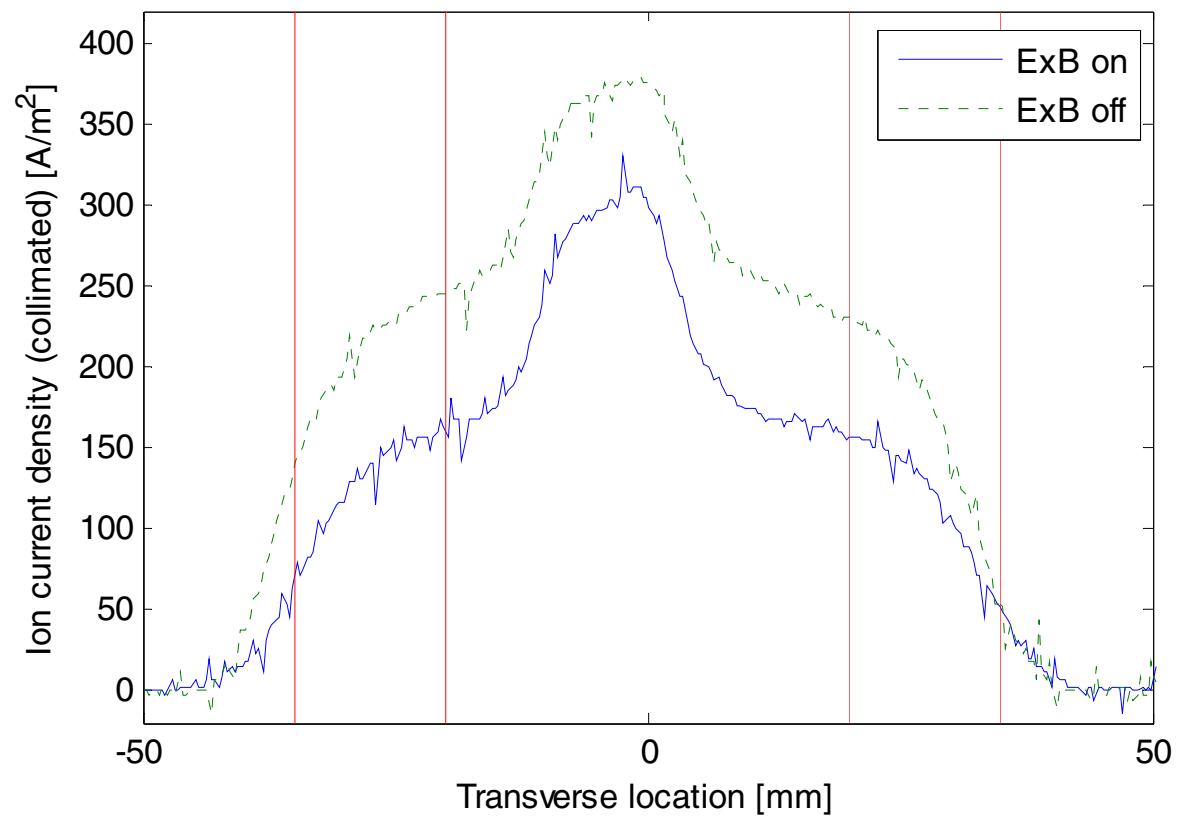

Figure 8 - Transverse scans at $200 \mathrm{~W}$, angle $=0^{\circ}$, axial distance $=125 \mathrm{~mm}$, with ExB probe turned on and off. When the ExB filter is off, all velocities are accepted (subject to the acceptance angle). When the ExB filter is on, only high 
velocity ions are accepted.

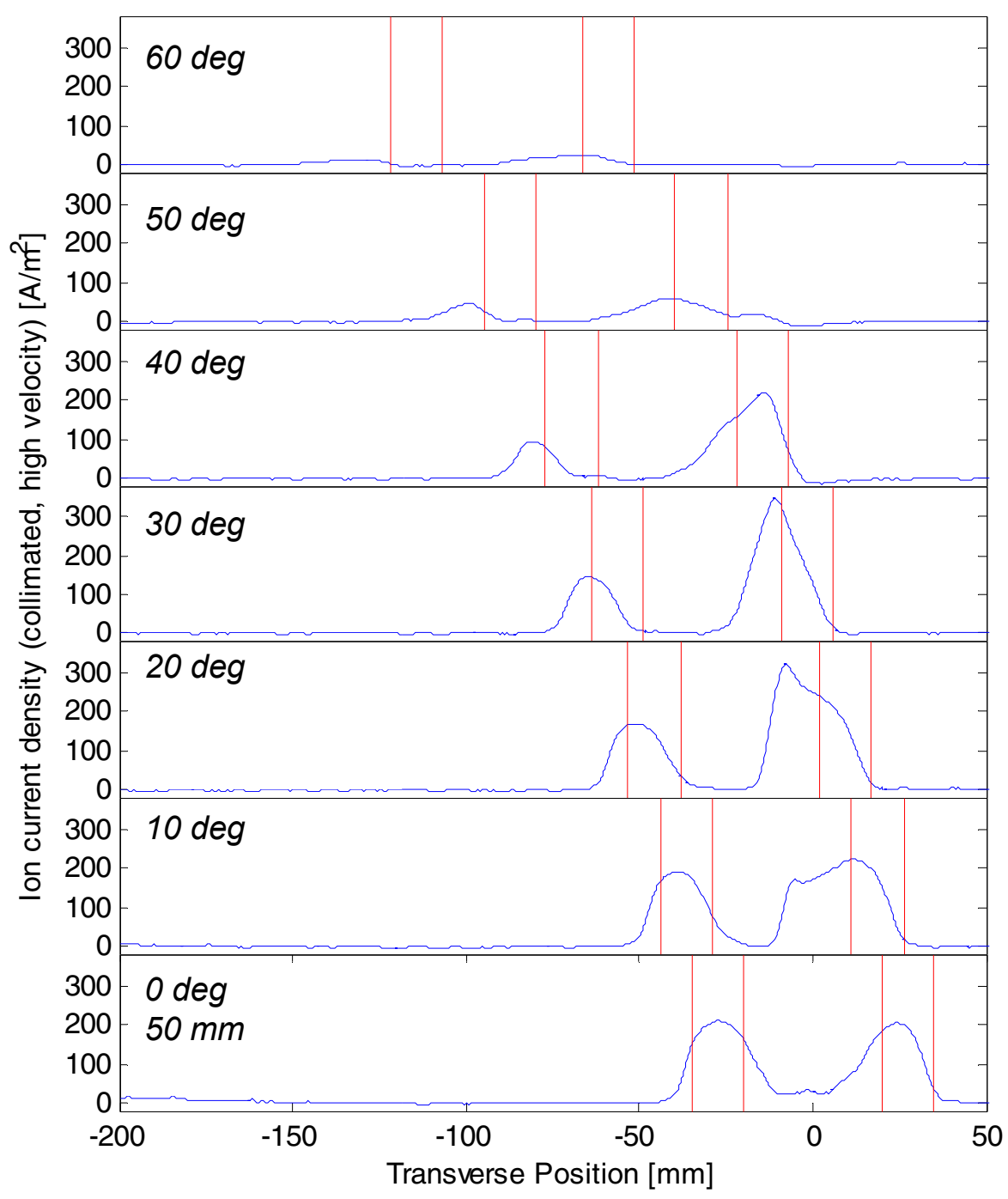

Figure 9 - Transverse ExB scans at $200 \mathrm{~W}$, axial distance $=\mathbf{5 0} \mathrm{mm}$. Each plot represents a different scan angle. Projected channel locations are plotted in red.

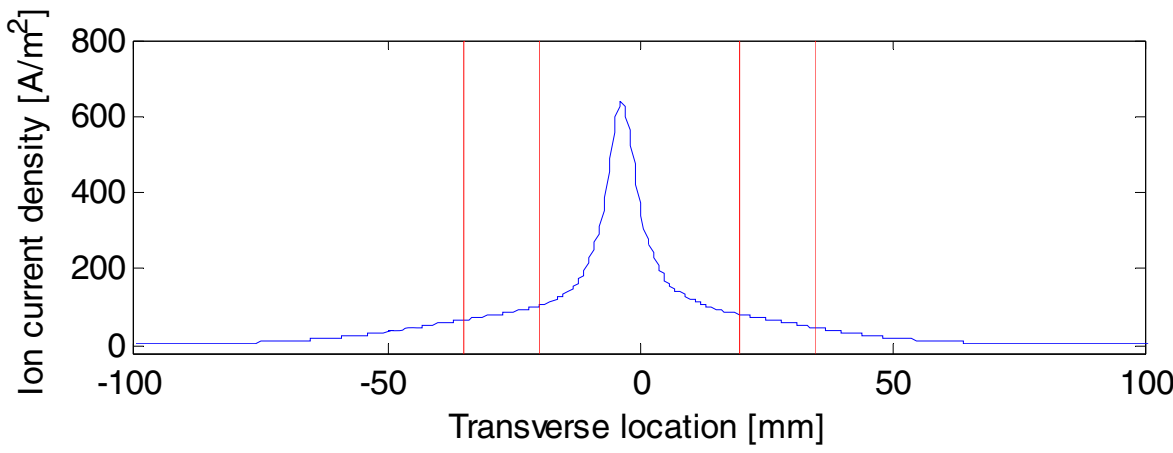

Figure 10 - Faraday probe scan at $200 \mathrm{~W}$, axial distance $=50 \mathrm{~mm}$. Projected channel locations are plotted in red. 


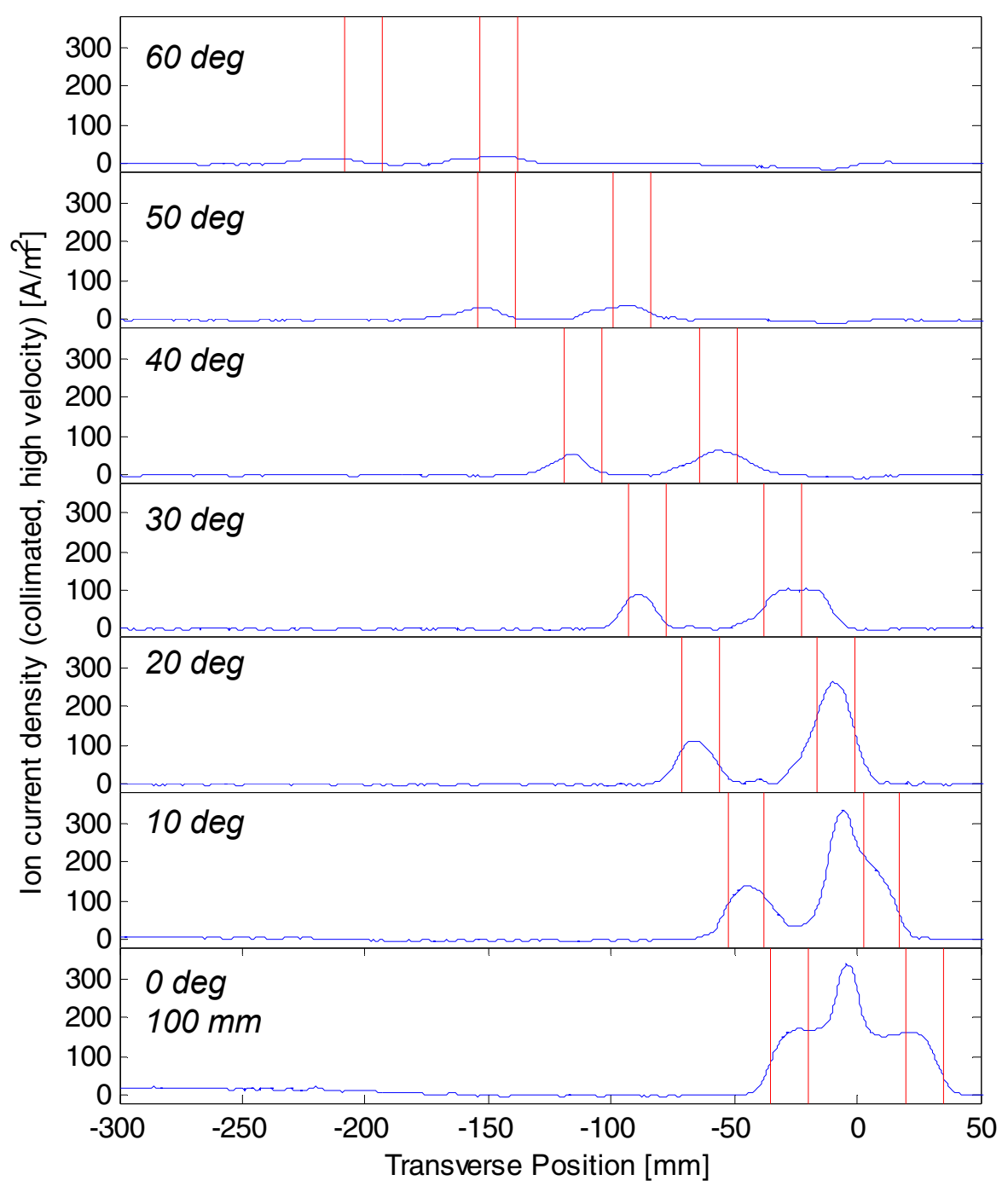

Figure 11 - Transverse scans at $200 \mathrm{~W}$, axial distance $=\mathbf{1 0 0} \mathrm{mm}$. Each plot represents a different scan angle. Projected channel locations are plotted in red.

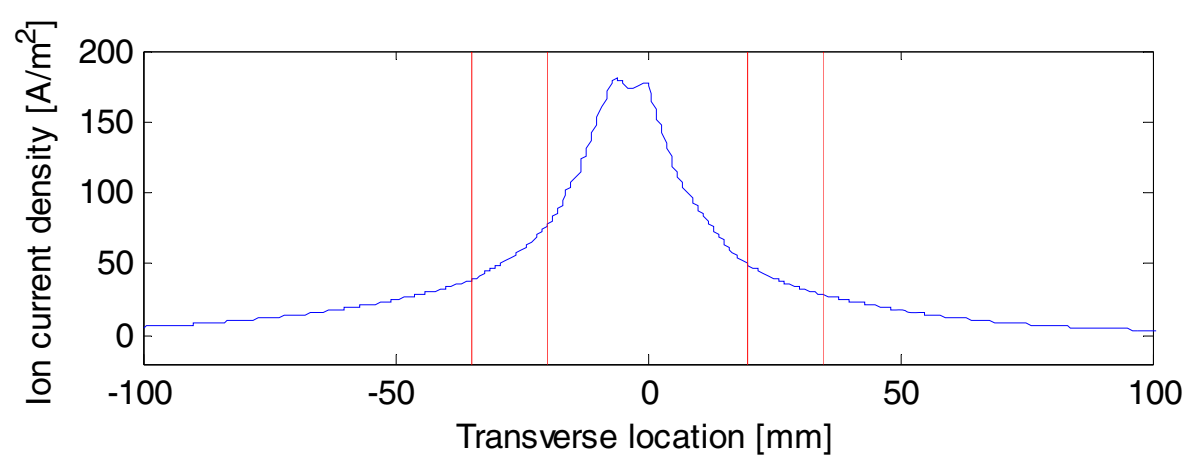

Figure 12 - Faraday probe scan at $200 \mathrm{~W}$, axial distance $=100 \mathrm{~mm}$. Projected channel locations are plotted in red. 


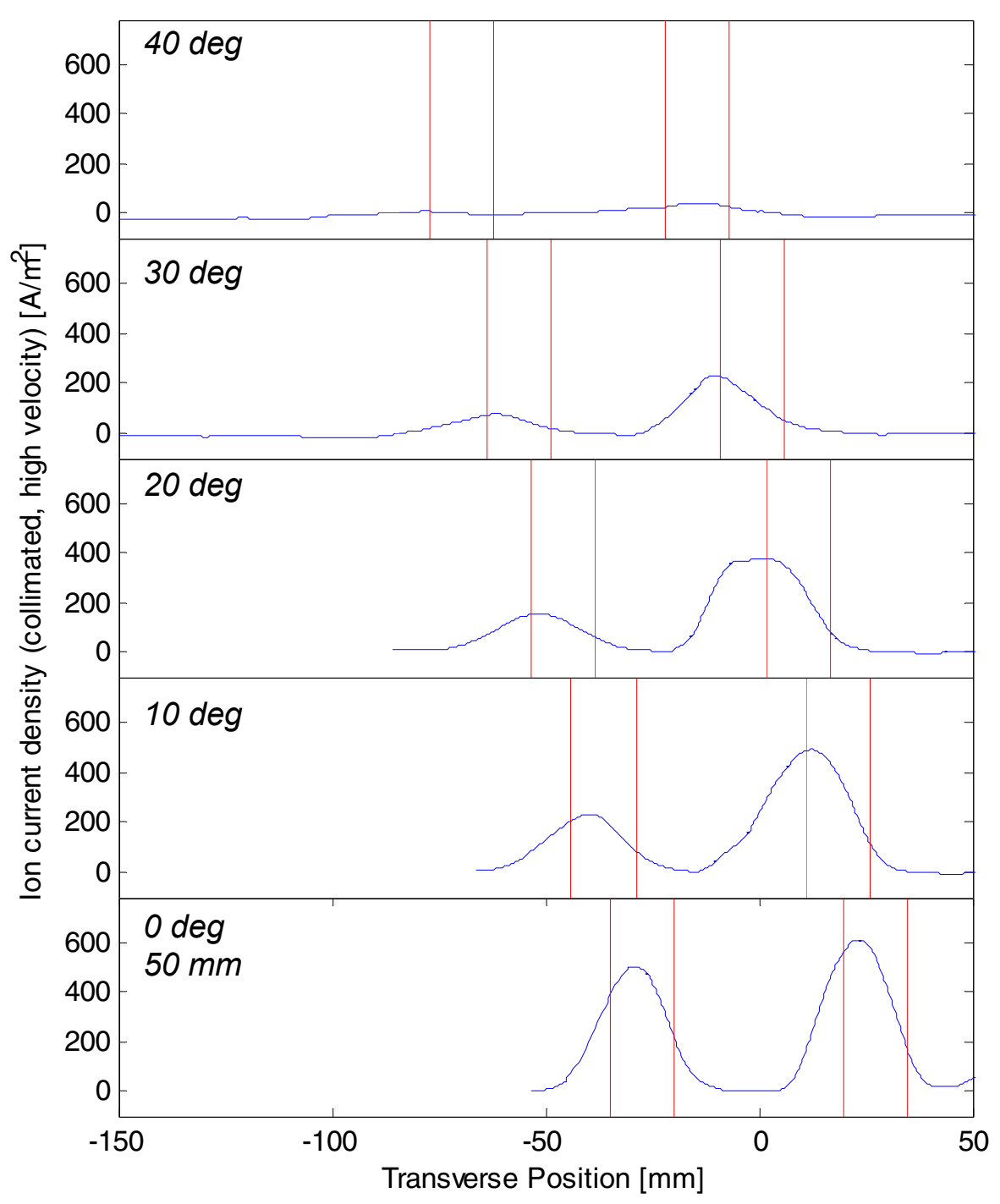

Figure 13 - Transverse scans at $650 \mathrm{~W}$, axial distance $=\mathbf{5 0} \mathrm{mm}$. Each plot represents a different scan angle. Projected channel locations are plotted in red.

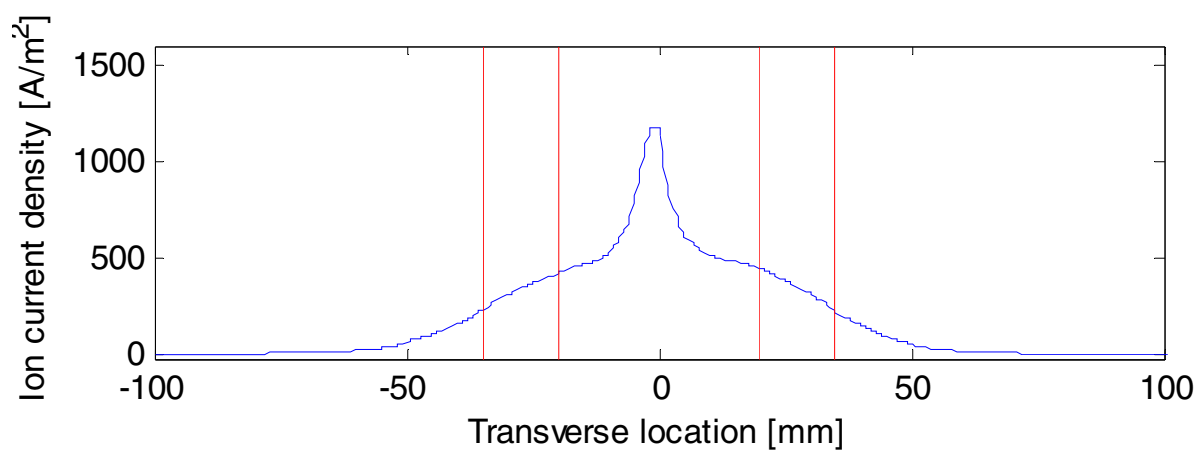

Figure 14 - Faraday probe scan at $650 \mathrm{~W}$, axial distance $=50 \mathrm{~mm}$. Projected channel locations are plotted in red. 


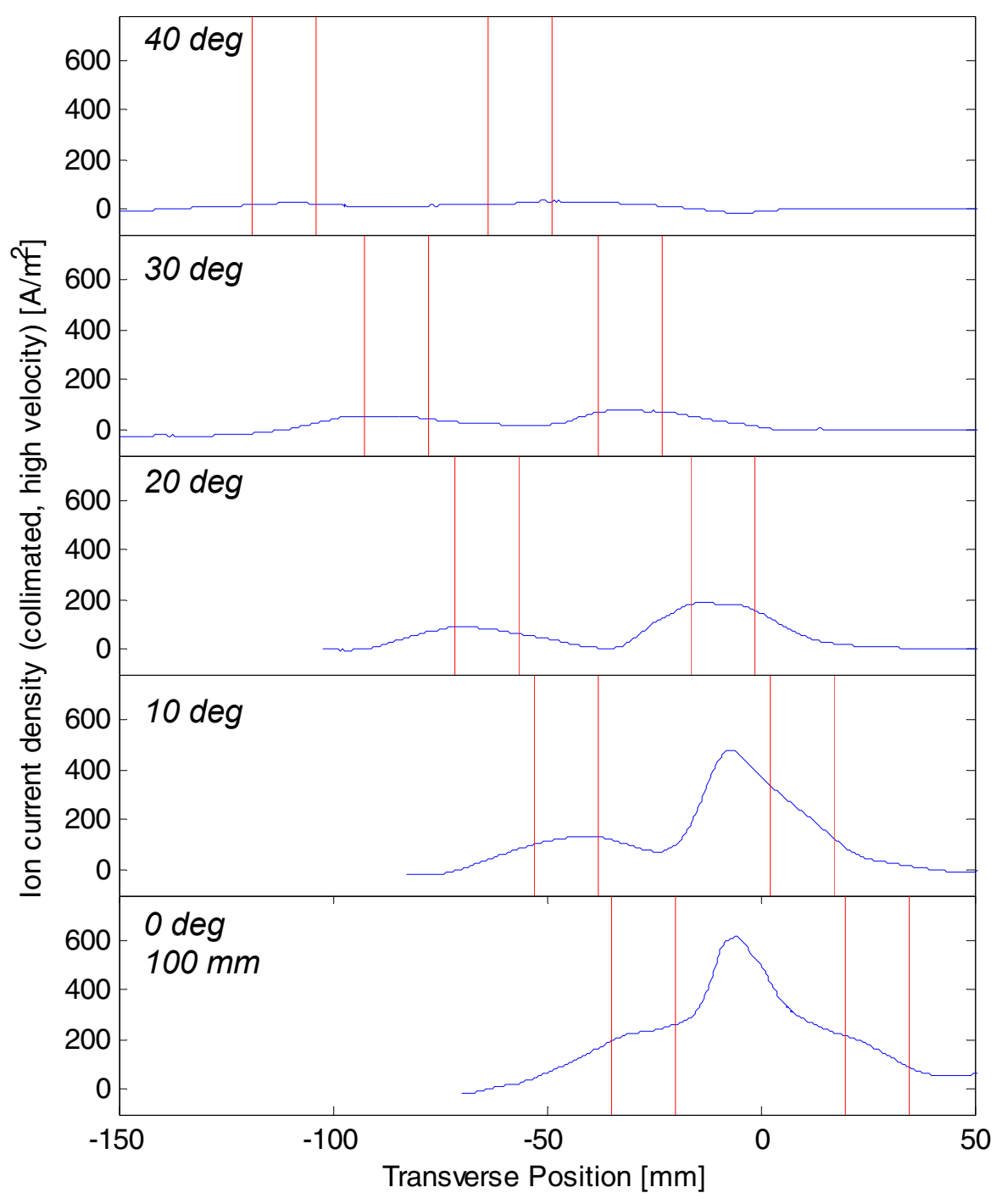

Figure 15 - Transverse scans at $650 \mathrm{~W}$, axial distance $=100 \mathrm{~mm}$. Each plot represents a different scan angle. Projected channel locations are plotted in red.

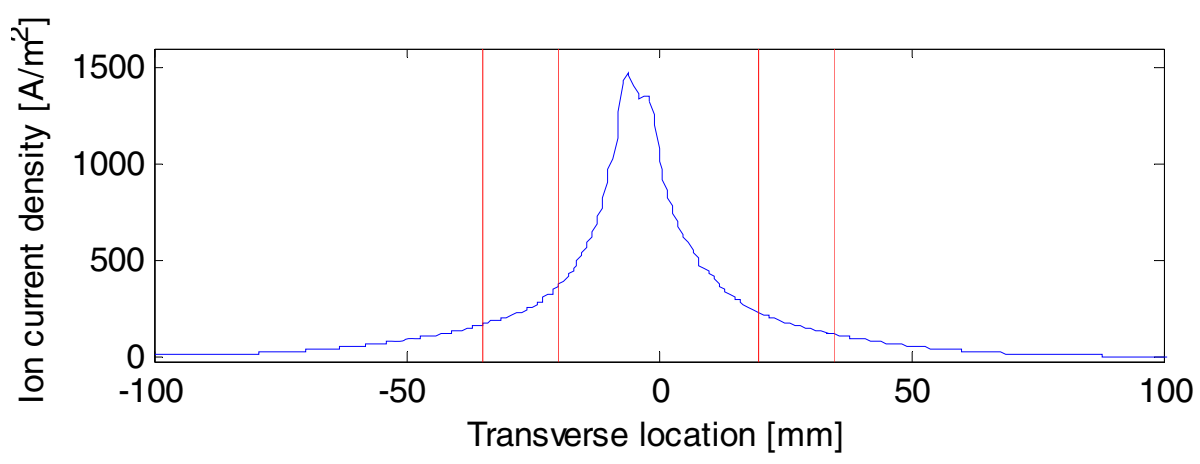

Figure 16 - Faraday probe scan at $650 \mathrm{~W}$, axial distance $=50 \mathrm{~mm}$. Projected channel locations are plotted in red. 


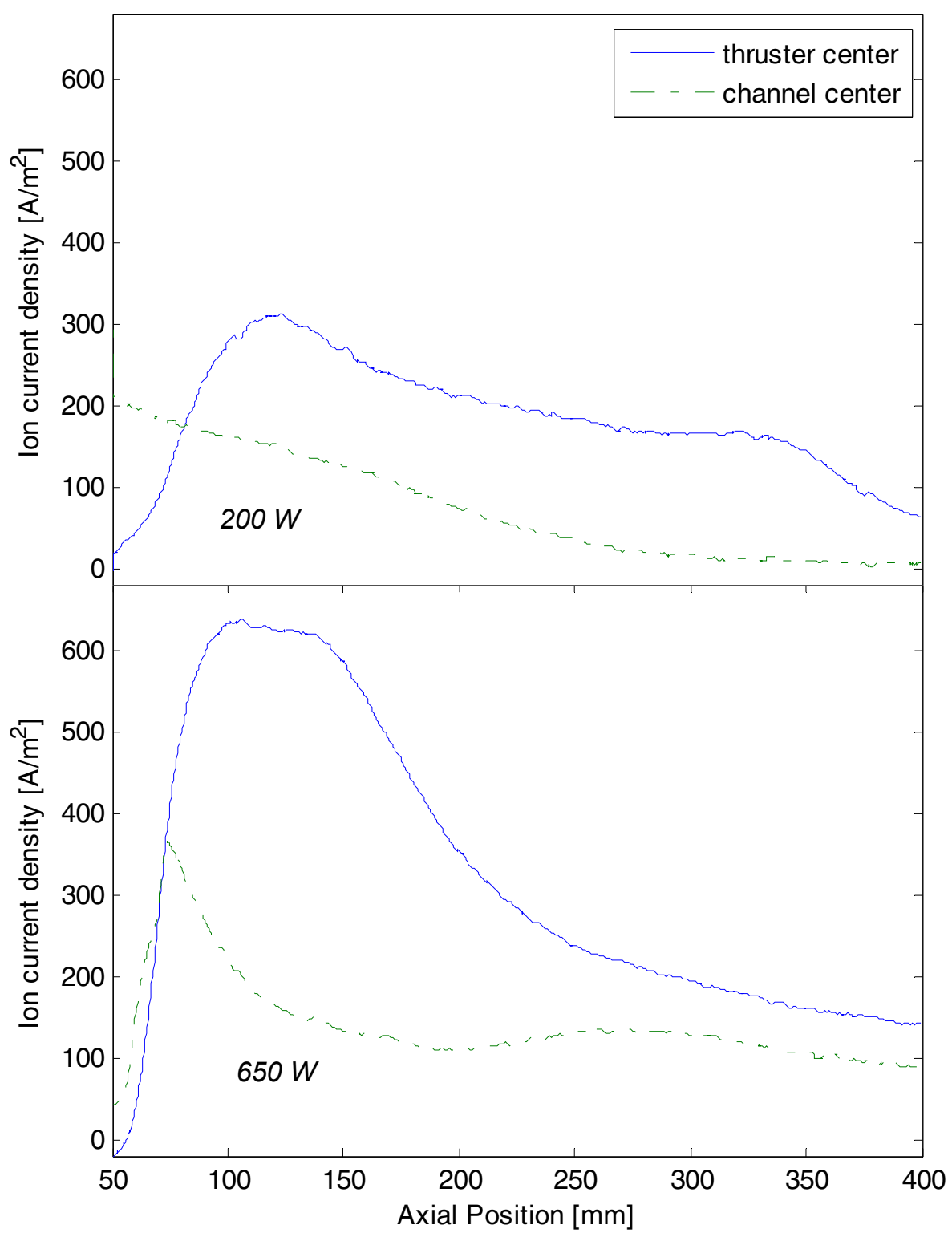

Figure $17-$ Axial scans at 200 (top) and $650 \mathrm{~W}$ (bottom), angle $=0^{\circ}$. 


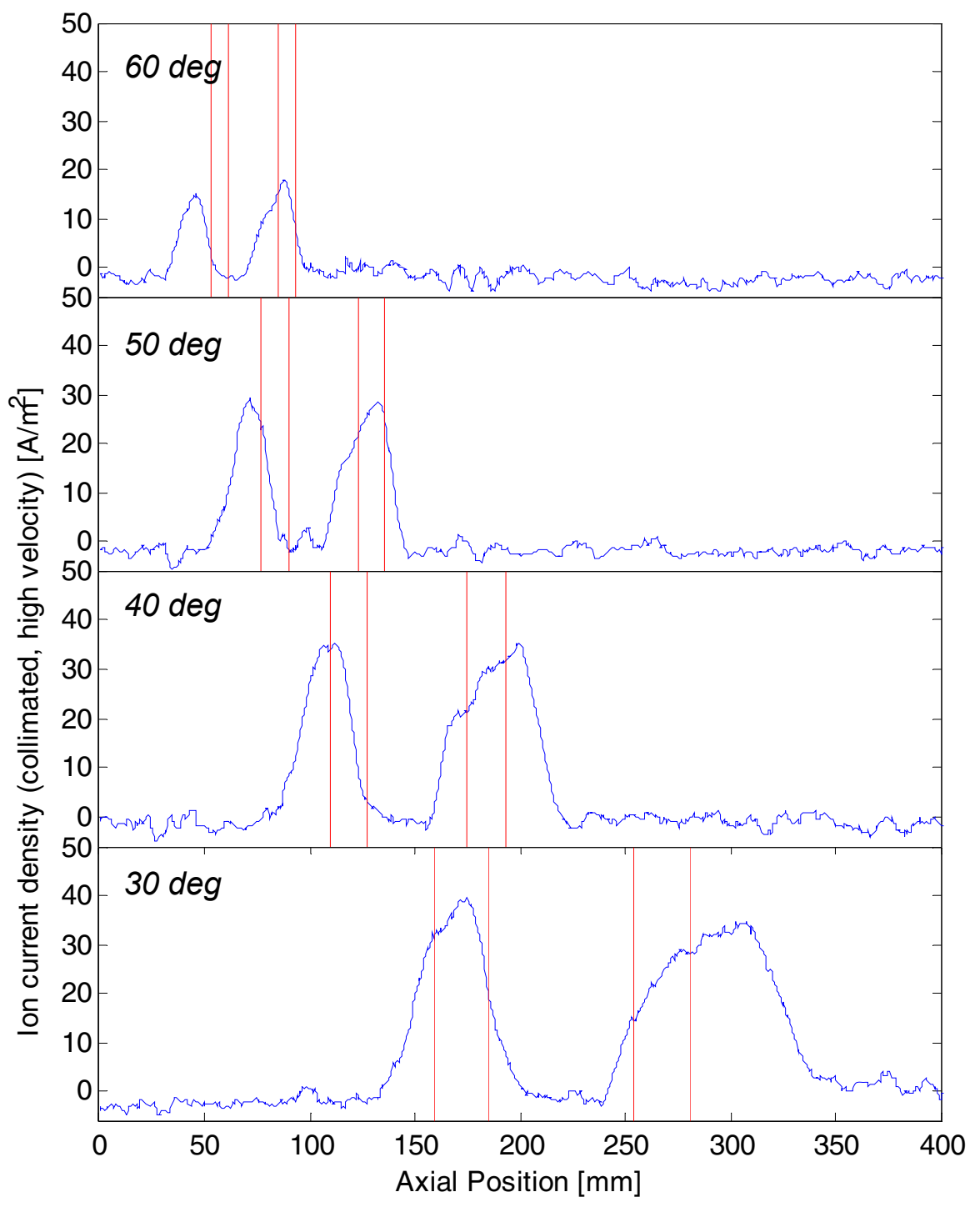

Figure 18 - Axial side scans at $200 \mathrm{~W}$, transverse distance $=\mathbf{- 1 2 7} \mathbf{m m}$. Each plot represents a different scan angle. Projected channel locations are plotted in red. 

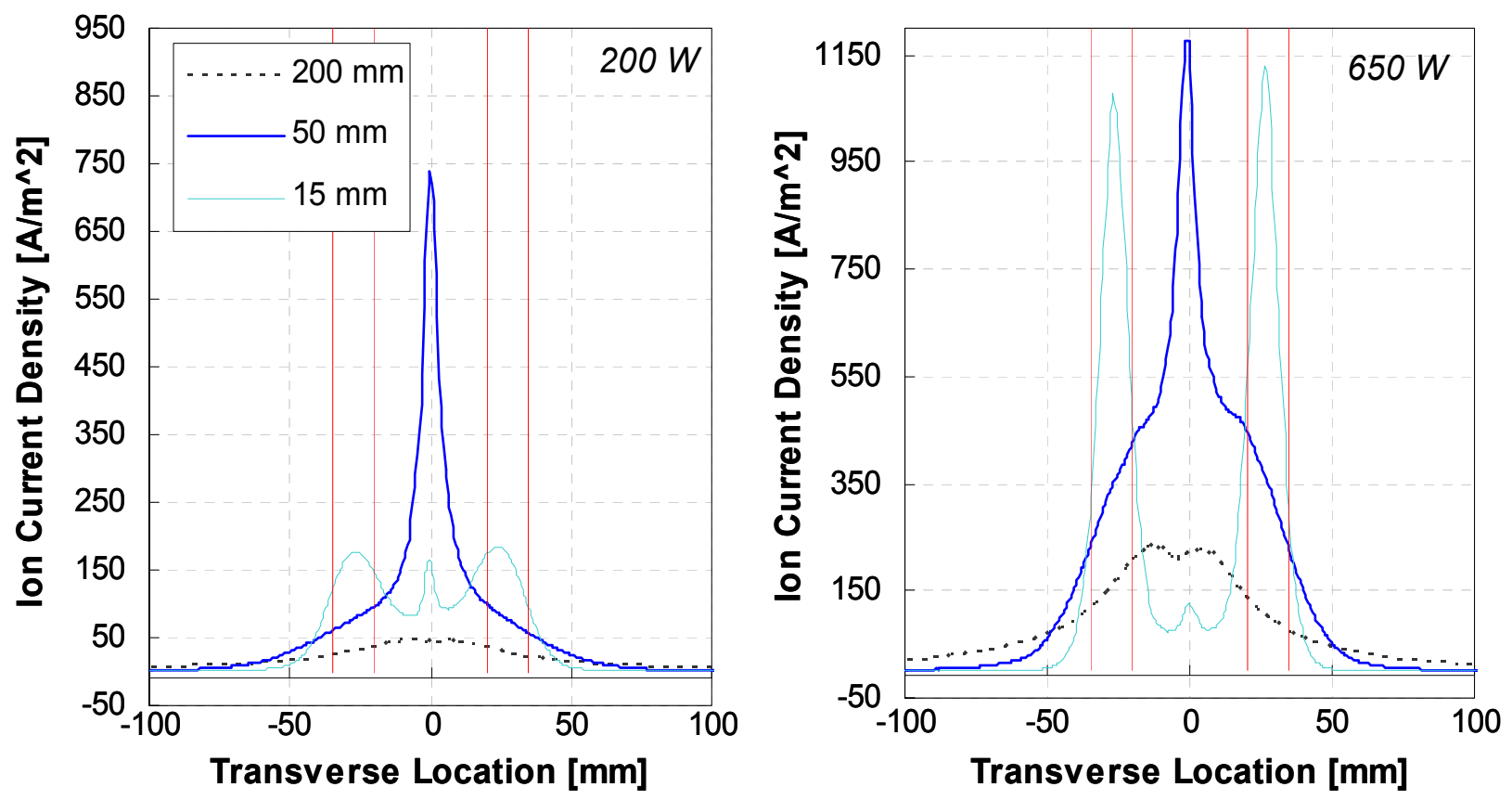

Figure 19 - Faraday probe scans at $200 \mathrm{~W}$ (l) and $650 \mathrm{~W}(\mathbf{r})$, angle $=0^{\circ}$. Channel locations are plotted in red. 